\title{
A Review on Economical Health and its Outputs
}

\author{
Vinay $\mathbf{V}^{1^{*}}$, Sriteja $\mathbf{V}^{2}$, Hemalal $\mathbf{R}^{3}$, Damodar $\mathbf{R}^{4}$, Mukesh $\mathbf{K}^{5}$ and Satyam $\mathbf{S}^{6}$ \\ ${ }^{1} P G$ Diploma Student, Andhra Pradesh Productivity Council, Hyderabad, Andhra Pradesh, India \\ ${ }^{2}$ Depatment of Life Sciences, University of Wolverhampton, Wolverhampton, UK \\ ${ }^{3}$ Department of Bioinformatics, School of Life Sciences, University of Hyderabad, India \\ ${ }^{4}$ Department of Pharmacy, Vignan Institutions, Vizag, India \\ ${ }^{5}$ Department of Bioinformatics, SV University, Tirupathi, India \\ ${ }^{6}$ Department of Biotechnology, Mahatma Gandhi University, Nalgonda, India
}

*Corresponding author: Vinay V, PG Diploma Student, Andhra Pradesh Productivity Council, Hyderabad, Andhra Pradesh, India; Tel: 91-9966617418; E-mail: v.vinaychandra@rediffmail.com

Rec date: May 16, 2014; Acc date: May 23, 2014; Pub date: May 31, 2014

Copyright: (c) 2014 Vinay V, et al. This is an open-access article distributed under the terms of the Creative Commons Attribution License, which permits unrestricted use, distribution, and reproduction in any medium, provided the original author and source are credited.

\begin{abstract}
The health economics now a days been higher around the world where each and every individual spends a lot in it. This paper explains the current statistics on health economics and outcome research in the current scenario around the world. All the information with statistical analysis was explained out clearly in pictorial representations. Business generation for health economics has shown higher around the world.
\end{abstract}

Keywords: Health Economics; Financial Markets; Health care

\section{What is HEOR?}

A perspective to analyze and understand situations relating to health. Health Economics (HE) is a branch of economics concerned with issues related to efficiency, effectiveness, value and behavior in the production and consumption of health and health care. It is a central component to explain product values in the market for clinical efficacy, real-world data, and patient life reports, costs of various treatments, budget impact, and cost-effectiveness models. HE is concerned with how resources are allocated and used in different health systems [1-4].

\section{Global Market $=$ ? Billion Dollars}

In Current scenario, stakeholders are increasingly relying on HE to understand fully about the product values in healthcare department (clinical practice) around the world. HEOR mainly helps pharmaceuticals and device manufacturers to communicate the value of their innovations to stakeholders around the market. Total expenditures in 2013 in U.S

- $\$ 2,800$ billion

- $\$ 8,900$ per capita (Based on population of 316 million)

- $17.9 \%$ of GDP (Based on GDP of $\$ 15,700$ billion)

\section{Location of Business Generation (India and Abroad)}

The Global Economy is now growing faster than the Global Gross Domestic Product. Source of Funds generation will be from [5-7].

- $50 \%$ public and $50 \%$ private.

- Only $11 \%$ is out-of-pocket. Third payment is key feature of health market.
Current status of Economical health outputs around world was mentioned in below Figure 1:

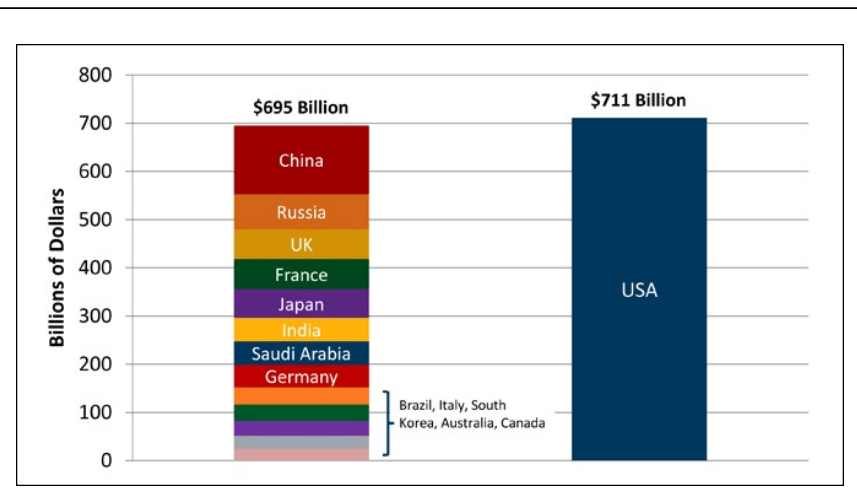

Figure 1: Current status of Economical health outputs around world.

\section{Health Care Financing Market in USA}

According to the report given by the medicare and Medicaid in 2013 states that the total health care costs were $17.9 \%$ gdp in 2011 , similar in the both the years 2010 and 2009 but the health care cost $\%$ is up by $13.8 \%$ gdp in 2000 .

According to the report of world health organization (WHO) USA is spending $15.2 \%$ of its gdp on the health care.

The surveys expect the usage of health care will increased and by 2017 its going to be $19.5 \%$ of the country's gdp. \% calculations on each dollar from each dollar the following $\%$ will be taken by the following departments.

- Hospital care $31 \%$ 
- Physician $21 \%$

- Pharmaceuticals $110 \%$

- Dental $4 \%$

- Nursing homes $6 \%$

- Home health care 3\%

- Other retail products $3 \%$

- Administrative cost 7\%

- Other professional studies $6 \%$

\section{Phase of Growth (Start, growth, Stationary, Death) 2020}

From a Public Health point of view, health economics is used to analyze issues of health and health care. But from an economics point of view, economical health is simply one of the topics to which economic principles and methods can be applied. The principles of health economics setting out how they might be interpreted in the context of health and health care (Figure 2).

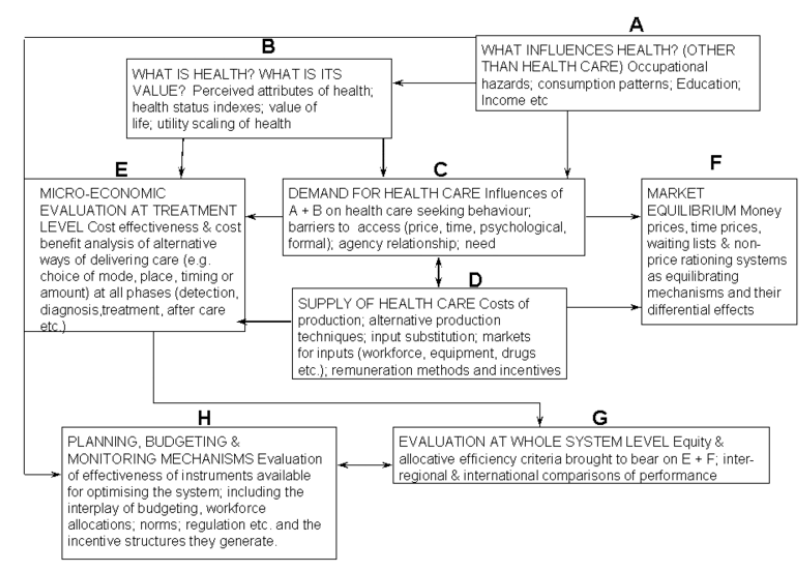

Figure 2: Flow chart for economical health techniques.

Five facts about new medical technology. First, new technologies will improve the quality of medical care by improving health outcomes in every clinical use. Second, many of the new technologies were ineffective or redundant and do not improve health outcomes. The trouble arises to discriminate between effective and ineffective technologies at the time they introduced. Third, new technologies proceeds, on balance, health care costs were added. Some technologies may actually reduce costs by replacing more expensive alternatives or preventing expensive health consequences, but this is to increase the overall costs. Fourth, up to now the incentives and regulations built into the American health care sector lead to inappropriate diffusion of technologies will be under diffusion of effective and cost-effective technologies. Currently Reimbursement systems, legal considerations, professional reward structures, and patient demands all contribute to the problem. The fifth will be inescapable fact about new medical technology is that the American public cannot get enough of it. They demand the best and top newest from our providers to oblige.

\section{Five Health Care Markets}

- Health care financing market

- Physician and nurses services market

- Institutional services market

- Input factors market

- Professional education market

\section{Key Players}

Following are some of the key players compitating for health economics and outcome research.

- The Hastings Center [8]

- Covance [9]

- Base Case [10]

- Optum [11]

- Pharmacoeconomics [12]

- Foundation for Health Services Research [13]

- National Trauma Research Institute [14]

- AHRQ [15]

- pcori [16]

- American Heart Association [17]

\section{Man Power}

HEOR depends freely on man powe4r which are as follows:

\section{Some components of supply}

- Health care providers for total practicing

- Health professional schools for total students

- New technologies

- Medical equipment

- Pharmaceuticals

\section{Some influences on supply}

- Restrictions on drug developments

- Medical school accreditation

- Licensing requirements

\section{Technologies Used}

This was explained in the below Figure 3.

\section{Where are the Services Provided across the World \\ [18-21]}

- Health technology assessment is ensuring coordination for greater provincial.

- Involving more stakeholders in both its projects and its dissemination activities.

- Evaluations were conducted in coverage with evidence development.

- Engaging in more Comparative Effectiveness. 


\section{Key Issues/Challenges Facing HEOR}

- The health care industry will benefit greatly from economic analysis.

- More than many other areas of economics this theory needs to be modified or extended to accommodate institutional features [22].

- Particular health consumers are buying a product which they know little about (information) with someone else's money (thirdparty payment) due to insurance (uncertainty).

- The high current issues always include the increasing cost of health care [23].

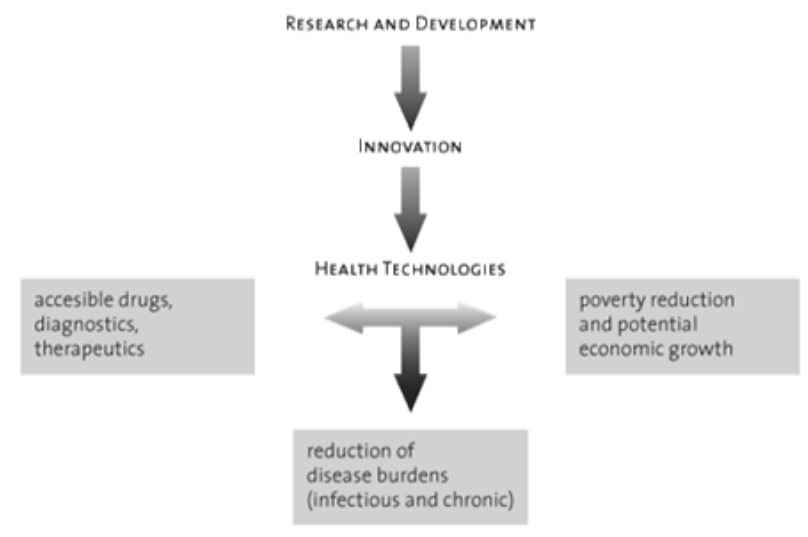

Figure 3: Potential impact of Technological innovation of Global Health.

\section{Business Forecast}

Following countries follows different policies for HEOR [24].

- Romania - Advising the national pharmaceutical trade association about the implications of NICE International's recommendations about pricing and a future HTA system.

- Russia - Interviewing federal and regional government agencies to understand current approaches to, and planned development of HTA, and subsequently advise a client about engaging with local payers and other key stakeholders during market entry and product development.

- Spain - Liaising with payers on ways to 1) improve partnerships with life science companies before and after product launch and 2) discuss international pharmaceutical pricing policies.

- Sweden - Exploring the national use of value based pricing through discussion with local pharmaceutical industry experts.

- Switzerland - Conducting an pharmaceutical industry survey on medicines pricing and reimbursement policies.

- UAE - Developing methods to elicit health-state values from the general public in the United Arab Emirates in collaboration with local academics and the pharmaceutical industry.

- UK - Working with the Department of Health and NICE on the creation of "value-based pricing" mechanisms and advising clients on its effect on products in their pipelines.

- USA - In collaboration with a US research organisation, gathered perspectives from US payers and key stakeholders on how comparative effectiveness research (CER) will affect drug development by the year 2020 .

- France - In discussion with local experts, assessing the impact of local HTA and pricing and reimbursement reforms on the market access of two products in phase III clinical trials.

- Germany - Monitoring and assessing the impact of AMNOG since its inception on a specific company's product pipeline.

- India - Using simulation analysis, explored the implications of adopting differential pricing for pharmaceutical products based on individual countries' income levels. Feasibility of adopting differential pricing in emerging markets was assessed jointly with company affiliates in a number of these territories; included interviews with stakeholders from non-governmental, public and global organisations.

- Italy - With local experts, assessing inefficiencies in the national health care system to provide a high-level health care policy agenda for solving these inefficiencies.

- Netherlands - Conducting a pharmaceutical industry survey on medicines pricing and reimbursement policies .

- Poland - Assessing changes to the national medicines pricing system.

- Spain - Liaising with payers on ways to 1) improve partnerships with life science companies before and after product launch and 2) discuss international pharmaceutical pricing policies.

- Sweden - Exploring the national use of value based pricing through discussion with local pharmaceutical industry experts.

- Switzerland - Conducting an pharmaceutical industry survey on medicines pricing and reimbursement policies.

- UAE - Developing methods to elicit health-state values from the general public in the United Arab Emirates in collaboration with local academics and the pharmaceutical industry.

- UK - Working with the Department of Health and NICE on the creation of "value-based pricing" mechanisms and advising clients on its effect on products in their pipelines.

- USA - In collaboration with a US research organisation, gathered perspectives from US payers and key stakeholders on how comparative effectiveness research (CER) will affect drug development by the year 2020 .

- Netherlands - Conducting a pharmaceutical industry survey on medicines pricing and reimbursement policies.

- Poland - Assessing changes to the national medicines pricing system.

- Qatar - Gathered insights through interviews with local experts and assessed the likely impact of options to change financial arrangements for health care.

- Romania - Advising the national pharmaceutical trade association about the implications of NICE International's recommendations about pricing and a future HTA system.

- Russia - Interviewing federal and regional government agencies to understand current approaches to, and planned development of HTA, and subsequently advise a client about engaging with local payers and other key stakeholders during market entry and product development.

\section{Resources to Meet Business Priorities}

Two types of resources can be implemented like Direct and Indirect rationings. 
In indirect rationing expenditure controls are imposed to restrict budgetary obligations to affordable level. No specific health priorities (diseases or interventions) are targeted when imposing these controls. Further, the budget-holder, which is usually a governmental figure is responsible for rationing the resources for care. The main disadvantages of this form of rationing are:

- In resources poor nations quality of care can be lowered.

- The budget will be captured by politically powerful health providers leading to the exclusion of vulnerable groups from adequate care [25].

With direct or explicit rationing health care priorities are first determined by following a set of criteria that considers political, social and cost-effective factors. Once the priorities are established available resources are rationed to meet the unique requirements of each priority. Rationing explicitly is unique from imposing expenditure controls because it rations resources by directly targeting specific priorities.

- Explicit rationing will remain cost-effective by considering costefficiency while determining which health priorities to ration for.

- Expenditure controls will remain cost-effective by immediately imposing budgetary restrictions then rationing resources for nonspecific health priorities

\section{Other Statistics}

Statistics were explained in Figures 4-6.

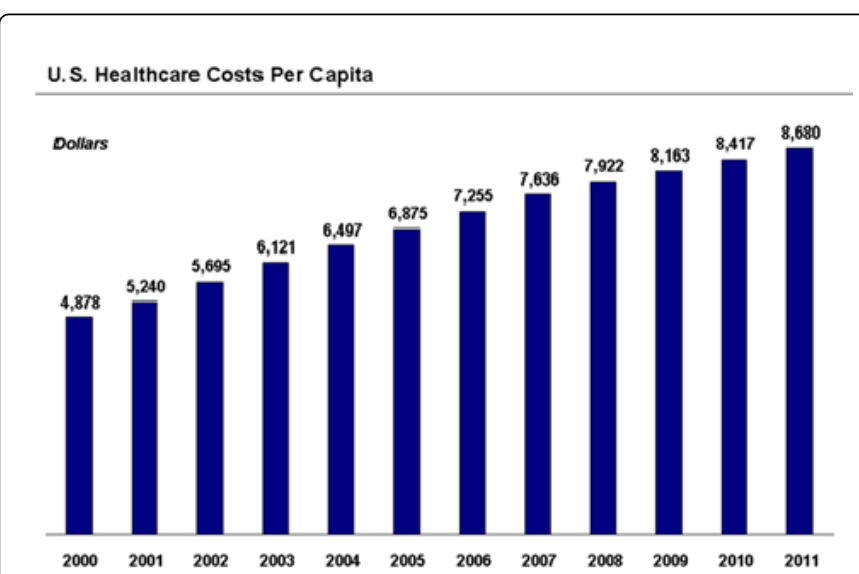

Figure 4: U.S. Healthcare Costs per Capita 2000-2011.

\section{Conclusion}

Current Scenario for Health economics and outcome research was presented above with all pictorial formats.

From the above review USA stood high among all countries in generating income on health care. Investment and spending were higher when compared with all fields of revenue generations. Still more research was carried on health care products around the world.

\section{Acknowledgement}

Every author has contributed equally.

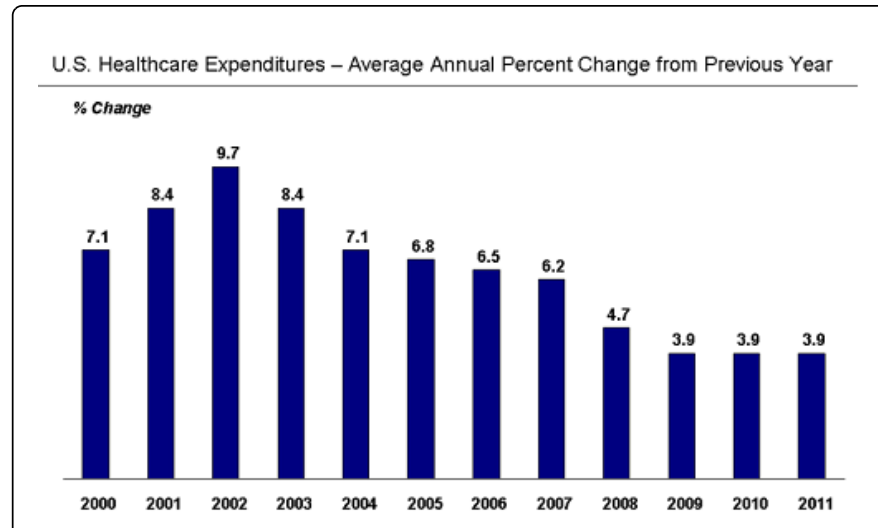

Figure 5: U.S. healthcare costs exceed those of other countries, relative for the size of the economy or GDP.

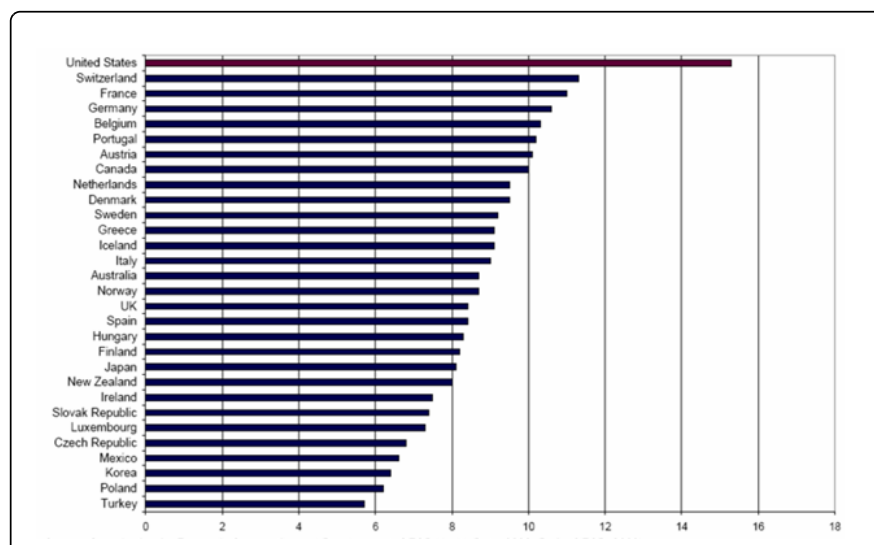

Figure 6: Health care spending as \% GDP.

\section{References}

1. Huang W, Chen Y, Song W (2013) Optimal Fiscal Equalization under Asymmetric Information. J Glob Econ 1: e103.

2. http://www.healtheconomics.com/

3. Spruk R (2013) Economic Growth and Income Convergence in Transition: Evidence from Central Europe. J Glob Econ 1: 104.

4. Majelantle RG, Navaneetham K (2013) Migration and Fertility: A Review of Theories and Evidences. J Glob Econ 1: 101.

5. Tsen WH (2014) Exchange Rate and Central Bank Intervention. J Glob Econ 2: e104.

6. Cañete LY (2014) Lessons on Gender Responsive Governance Gleaned From the Nature and Focus of a University Community Extension Program. J Glob Econ 2: 109.

7. Yamada T, Yamada T, Chen CC, Zeng W (2013) Overwork and Adverse Effects on Health. J Glob Econ 2: 106.

8. http://www.thehastingscenter.org/Publications/BriefingBook/ Detail.aspx?id $=2178$

9. http://www.covance.com/products/commercialization/market-access/ consulting/gheor.php

10. http:/basecase.com/articles/heor-value-in-healthcare/

11. http://www.optum.com/life-sciences/develop-evidence/healtheconomics-outcomes-research.html

12. http://www.ispor.org/links_index.asp

13. http:/www.academyhealth.org/files/publications/healthoutcomes.pdf 
Citation: Vinay V, Sriteja V, Hemalal R, Damodar R, Mukesh K, et al. (2014) A Review on Economical Health and its Outputs. J Glob Econ 2: R1-001. doi:10.4172/economics.1000R1-001

Page 5 of 5

14. http://epocaustralia.cochrane.org/improving-healthcare-and-patientoutcomes-through-research-translation

15. http://www.ahrq.gov/research/findings/factsheets/outcomes/outfact/

16. http://www.pcori.org/funding-opportunities/funding-announcements/ improving-healthcare-systems/

17. http://circoutcomes.ahajournals.org/content/2/1/1.full

18. Immanuelraj TK, Dastagiri MB, Sajesh VK (2014) Growth and Instability of Onion Production in Maharashtra, India. J Glob Econ 2: 107.

19. Majelantle RG, Keetile M, Bainame K, Nkawana P (2014) Knowledge, Opinions and attitudes towards HIV and AIDS among Youth in Botswana. J Glob Econ 2:108.
20. Lai PY, Teng J (2013) Five Policy Options in Face of Euro Crisis. J Glob Econ 1:e101.

21. Teng J, Lai PY (2013) Globalization, New International Political Economy and Global Economics. J Glob Econ 1:e102.

22. Delgado FJ (2013) Are Taxes Converging in Europe? Trends and Some Insights into the Effect of Economic Crisis. J Glob Econ 1:102.

23. Pradhan R (2013) Evaluation of Micro Finance in Harda and Hoshangabad Districts of MP. J Glob Econ 1:103.

24. http://www.healtheconomicsreview.com/

25. http://helid.digicollection.org/en/d/Jh0197e/4.html 